\title{
Why is the Flower of Youth So Red and Radiant?
}

\section{Zhengshun Han}

\author{
Wuhan Textile University, Hubei Province, Wuhan ,China.430073
}

hanzhengshun@126.com

Keywords: Timeline, lost, treasure, campus love, flower of youth

\begin{abstract}
The Thai Movie of Timeline is a clear manifestation of campus love that moves one into tears and stays unforgettable throughout one's whole life. It tells the story of a handsome young guy of Tan who was raised up by his early widowed mother ---Matt---through thick and thin in the country, but upon entering university, he disagreed with her over the issue of staying in hometown or go to the capital to pursue his study. In university he was sandwiched between two lovers of the graceful Oon and the talented June whom he does not cherish as he should have. In the end, Oon simply goes on with what she wants: "hectic and happy", and June sinks deep into the ocean while helping to save an almost drowned Japanese child on a pleasure boat.This paper aims to delineate this movie from four perspectives:(1).Familial mission is what we are born to accomplish.(2).Don't aim too high and wish for the impossible when young.(3).Treasure the friendship that fits you like a fiddle.(4).The director makes good use of the technique of foreshadowing or foresight and deliver some significant messages to us, to the writer's mind.The author sincerely hopes that this essay serves as reminder to the "lost"youngsters on campus.
\end{abstract}

\section{Introduction}

It is universally acknowledged that Thailand is a "Land of Smiles"[1], gentleness and hospitality. Thai smile and modesty embedded in Thai culture has created the unique Thai touch. [2].As a movie fan of western block busters, I happen to watch a Thai movie named Timeline (relased on Feb.2014) on Feb.14,2017--- Valentine's Day. It simply grabs my full attention and just knocks me out and fractures me from start to finish. These beautiful young faces, the azure sky, the tropical scenery etc. all baptize me from head to toe, like a breath of fresh breeze. This moving love story is even more gripping, nearly riveted in mind for ever. However, surfing the internet reveals little review of this movie:(1). The User Rating is 94 out 195 votes [3]. (2).Wanne regards it as a bit disappointing and not realistic, but she was struck by the beautiful scenes and moved to tears [4]. (3). Thai's youngsters are indeed good-looking. Why do we have after-sight,not foresight? Only after the loss of something can we realize its importance and value, perhaps it is because human nature makes it so [5]. In this paper. The author attempts to analyze this movie from four perspectives:(1).Familial mission is what we are born to accomplish . (2).Don't aim too high and wish for the impossible when young. (3). Treasure the friendship that fits you like a fiddle. (4).The director makes good use of the technique of foreshadowing or foresight and deliver some significant messages to us, to the writer's mind.The author sincerely hopes that this essay serves as reminder to the "lost "youngsters on campus.

\section{Familial Mission Is What We Are Born to Accomplish}

Matt, a single mother, remains gentle, kind and loyal to her dead husband. She makes a living by raising strawberry on a farm of her own. Her secret admirer, Watt, a tall handsome guy, always try his best to offer help by selling her strawberry. He has a car, so sometimes provides her with transportation from hometown to the capital to see her son. Upon entering university, he donates a new bike to Tan which proves to be very useful. Despite the much help he offers to her, she rejects his offer of marrying her indirectly. The worst thing is that , once, in poor health, and doing a lot of heavy work: making strawberry jam to bringing in some more money, she was hospitalized and inclined to sell her farm but finally determines not to do it so as to leave it as a legacy to her only son. When coming out of the hospital, she is discovered to have been writing letters to her dead husband 
all along. Her idea is that if you go on with fulfilling one's wishes, it seems like that one is still with you all the time. So, she faithfully manages the farm of her husband, weathers some periods of financial difficulties and wishes her son to carry on the business. When her son defies her wish, she gives in and has to face this harsh fact of his going to Bangkok to pursue his study. Fortunately, before graduation, her son transferred back home to study agriculture .This should be what his familial mission is against the backdrop of the strong Buddhist tradition in Thailand.

\section{Don't Aim too High and Wish for the Impossible When Young.}

In university, Tan undergoes tremendous physical and psychical transformations . As a country boy, he is well-built, big and broad, so he wears loose clothes. But once in Bangkok, he starts to change and follow fashions so as tO mix with his classmates and surroundings.His wearing a slim shirt that misfits him can serves as a telling instrument symbolizing this mentality. In class, he is once too late and so is June, a short but lively girl in his class. As a kind of punishment, students demand that they dress very oddly like a cat and dance before the whole class in a very weird fashion. They die a social death indeed.Then together they go to a movie directed by Oon, a tall, graceful and beautiful girl who knows what she enjoys doing in the school's club.Since this encounter on the corridor, he starts to focus his attention on Oon and tries to please her and court her at every conceivable opportunity. When they go to his beautiful hometown to shoot a movie for free food and board. Oon, as always, is busy with her own matters of shooting movie while he just does his best to provide conveniences.It seems that she is the right girl for him: rich, fashionable and graceful. However, as she is more mature and clearly aware of what she is doing it for, she just gives him a colorful ballpoint pen( actually June buys that) to do some cartoon as a token of friendship.Therefore, the writer deems that Tan is doing only daydreaming and tries to reach for what is beyond his grasp. They belong to different worlds and this state of affairs is pretty much doomed right from the start.

\section{Treasure Friendship that Fits You Like a Fiddle}

In sharp contrast to Oon, June is a nice, talented and thoughtful girl. After they know each other, they had some gatherings to make their life very romantic. The first thing is that they raise a cute dog and name it as "Can" for when they meet it, it has a string of cans attached to its tail by some someone mischievous. They just save it and makes it their own. The second thing is that they go to an exhibition and come across a beautiful painting titled"Deep Sea Star Light". Then they come to know that it is real painting of a portion of ocean in Japan. The third thing is that they go cycling to an island and spend a night there. They draw a big picture of Can there, and he just lies on it, so romantic and so dreamy. As is mentioned before, he is actually torn between these two girls. During his journey home to do the film- shooting, June, unlike Oon, is very considerate of his mother, and watches his home very carefully. She suddenly notices the love letter scribbled on the wall, and his mother tells her about its secret: Matt and Thun (father's name) both love it as their keepsake,which is the climax of this movie, the author thinks. While he is very hot with Oon, June, thanks to her academic brilliance, obtains a chance to study in Japan without his knowing. It is only when he realizes that Oon is out of his reach that he begins to pay attention to June, who has gone abroad. However, in Japan, while June is doing sightseeing of the "Deep Sea Star Light"on a pleasure boat, she sinks to the bottom of sea due to her effort to save a naughty boy. Subsequently, knowing this turn of events, Tan hopes to recollect some memories of their sweet past: looking at Can; visiting the exhibition but failed to find the painting; going to the island and lying again on the drawing of Can, etc.. All these won't do any good. Finally, he goes to Japan by himself to see that part of the ocean where she dies. Upon her death, she seems to visualize her going through the bright Timeline Tunnel to reach heaven. Only after something is done does he truly realise it cannot be undone. What a great loss it is to Tan! Whatever he does cannot bring back his lovely June who loves and cherishes him so dear.and above all, fits him like a fiddle. 


\section{The Director Makes Good Use of the Technique of Foreshadowing or Foresight and Delivers Some Significant Messages to Us.}

By viewing this movie for several times, it occurs to the writer that the director makes very good use of the technique of foreshadowing indeed. First of all, right at the outset, in the prologue, Matt and her young husband Thun were enjoying their romance. Once when they were doing the dishes, Thun deliberately asks Matt to cook the dish by herself even though he cooks better and more delicious, she was curious and wonders why, he just replies that in case one day he is gone, and this indeed comes true. Secondly, on their trip to the island, June wonders about what it is like to see the sea from the other side. Tan replies that it is totally dark, and you see nothing. Following that, she inquires : what about seeing stars in the center of the sea? Then the picture in the exhibition further strengthens their wish to see the star light in the center of the sea. At last, their dream come true when she goes to Japan to see the star light in the center of sea and Tan in the end to fulfill her wish of traveling around the world by cycling there.Thirdly, on their journey to the island, they both tell each other of their dreams: by staying in Bangkok, he accomplishes his dream of not wanting to stay home; not wanting to cultivate the land; not wanting to be somebody's shadow and it comes true while she said that when she was small child, she was almost drowned one time, and it is Oon who saves her life. The denouement is actually her being drowned in the place of her dream "Deep Sea Star light". Isn't this coincident or accidental,funny and interesting? It is nothing but full proof of the director's employing the technique of foreshadowing, in the writer's opinion.

Besides, to the writer's mind, the director delivers some significant messages to us through different characters. For instance,(1).On their island trip, June remarks that there are too many uncertainties in our life, so we should seize the time to do what we like to do before we don't have the chance. (2). When they were fixing their bike, the shop-owner offer to trade their old one for a brand new one for cherishing things past, June says that it is weird for people to have this mindset of changing the old for new and vice versa. She goes on to say that it is not always right for them to have something new.(3). Towards the end, when Tan feels deeply regretful and remorseful for his neglect of June, he utters that he knows that in life, there are not too many encounters, once missed, they cannot come back again. (4).Just as Matt remains strong and courageous enough carry on her husband's dream of doing the farming of strawberry, so Tan travels around the globe to go on fulfilling June's dream of doing it. In so doing, it is as if they would still be together and forever despite her departure[6], so on and so forth. These strong and clear messages are just the thing that director designs for us to remember and bear in heart for good, indeed very good lessons for the "lost "young people on campus.

\section{Conclusion}

As we all know, life is a one- way journey. Youth flashes away only once.Those golden times that we cannot go back to remain the sweetest memory to us.[7] The slightest mention of it would bring nostalgic recollections and memories of delicious thrill. Those fond, dreamlike adolescence make us suffer from a strong sense of loss and being left out of times. This period abounds in our revolt against parents; first-time stirrings of love and searing love letters; and self-styled ever-lasting friendship --some matters may be regretful, but not repentant; past trauma and depression once made us worn out both physically and psychically.Nevertheless, bitter memory still tastes sweet and delicious to us even now..The unspeakable sentiment remains to be a lifetime secret and asset.Those times beyond retrieval witnessed our youthful vigor and vitality and our growth. Isn't it so with this movie? We read ourselves in this movie, its sorrows and trauma, its regrets and repentance, its inspirations and timeless love symphony.don't you think so?

\section{References}

[1] Larry A Samovar,Richard E Porter,Edwin R. McDaniel. Communication Between Cultures.6e. Beijing:Peking University Press..2009.p.209. 
[2] Thai'stimeline.TheAustralian.May12010. http://www.theaustralian.com.au/archive/travel2015-prelife/thais-timeline/news-story/e487e87be7939cd19d5b9dda56d32cdf.

[3] Timeline-Thai Movie.http://asianwiki.com/timeline_-_Thai Movie.

[4] Wanne.Timeline--- a Thai Movie that made me cry. http://www.iamwannee.com/timeline-a-thaimovie-that-made-me-cry/

[5] Timeline:Aftersight ..http//movie.mtime.com/215656/reviews/7887007.html.

[6] Classic Passages of Timeline:.https://sanwen8.cn/p/19eE61.html.

[7] Xu Zhengfang..Not Understanding Without Experiencing.Beijing:China Publishing House of Overseas-Chinese. 2014.7. 